\title{
SHALLOW FLAWS UNDER BIAXIAL LOADING CONDITIONS, PART II: APPLICATION OF A WEIBULL STRESS ANALYSIS OF THE CRUCIFORM BEND SPECIMEN USING A HYDROSTATIC STRESS CRITERION'
}

\author{
Paul T. Williams, B. Richard Bass, and Wallace J. McAfee \\ Oak Ridge National Laboratory \\ Oak Ridge, Tennessee USA
}

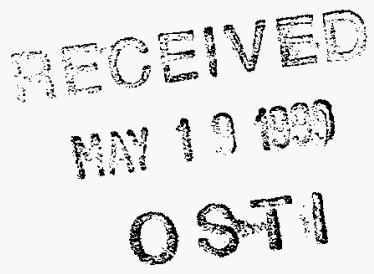

\begin{abstract}
Cruciform beam fracture mechanics specimens 1 have been developed in the Heavy Section Steel Technology (HSST) Program at Oak Ridge National Laboratory (ORNL) to introduce a prototypic, farfield, out-of-plane biaxial bending stress component in the test section that approximates the nonlinear biaxial stresses resulting from pressurized-thermal-shock or pressure-temperature loading of a nuclear reactor pressure vessel (RPV). Matrices of cruciform beam tests were developed to investigate and quantify the effects of temperature, biaxial loading, and specimen size on fracture initiation toughness of two-dimensional (constant depth), shallow, surface flaws. Tests were conducted under biaxial load ratios ranging from uniaxial to equibiaxial. These tests demonstrated that biaxial loading can have a pronounced effect on shallow-flaw fracture toughness in the lower transition temperature region for RPV materials. Two and threeparameter Weibull models have been calibrated using a new scheme (developed at the University of Illinois) that maps toughness data from test specimens with distinctly different levels of crack-tip constraint to a small scale yielding (SSY) Weibull stress space. These models, using the new hydrostatic stress criterion in place of the more commonly used maximum principal stress in the kernel of the $\sigma_{w}$ integral definition, have been shown to correlate the experimentally observed biaxial effect in cruciform specimens, thereby providing a scaling mechanism between uniaxial and biaxial loading states.
\end{abstract}

\footnotetext{
1 Research Sponsored by the Office of Nuclear Regulatory Research, U.S. Nuclear Regulatory Commission under Interagency Agreement 1886-8663-1W with the U.S. Department of Energy under Contract DE-AC05-96OR22464 with Lockheed Martin Energy Research Corp. The submitted manuscript has been authored by a contractor of the U.S. Government No. DE-AC0596OR22464. Accordingly, the U.S. Government retains a nonexclusive, royalty-free license to publish or reproduce the published form of this contribution, or allow others to do so, for U.S. Government purposes.
}

\section{INTRODUCTION}

Shallow-flaw fracture toughness data for reactor pressure vessel (RPV) materials in the lower transition temperature region exhibit greater scatter and higher mean values than the toughness data obtained from deep flaws because of reduced crack-tip constraint [1]. Uniaxial full-thickness clad beam tests [2] carried out by the Heavy Section Steel Technology (HSST) Program at Oak Ridge National Laboratory (ORNL) were used to quantify this shallow-flaw effect in specimens (using material taken from an RPV of a canceled nuclear plant) which are prototypic of RPV wall thickness and material properties. However, these uniaxial beam tests did not address the issue of nearsurface biaxial stress fields produced by pressurized-thermal-shock (PTS) or pressure-temperature (P-T) loading of an RPV (see Fig. 1). The out-of-plane biaxial stress component has the potential to increase constraint at the tip of a shallow crack and thereby reduce the shallowflaw fracture toughness enhancement.

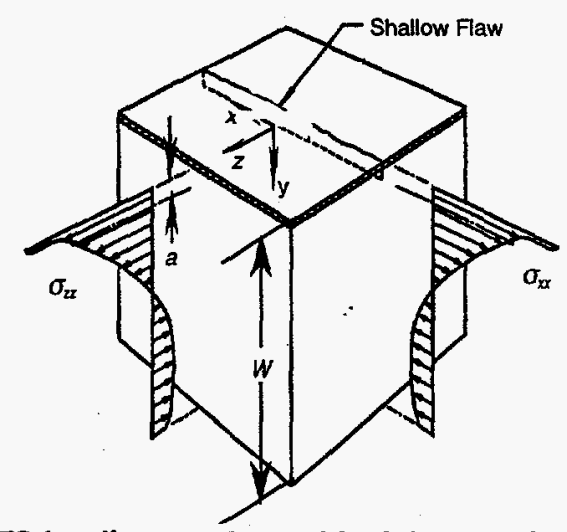

Fig. 1. PTS loading produces biaxial stress in an RPV wall with one of the principal stresses aligned parallel with the tip of the constant-depth shallow surface flaw. 


\section{DISCLAIMER}

Portions of this document may be illegible in electronic image products. Images are produced from the best available original document. 
Cruciform beam specimens [3-9] developed at ORNL introduce a prototypic, far-field, out-of-plane biaxial bending stress component in the test section that approximates the nonlinear stresses of PTS or P-T loading (see Fig. 2). The cruciform specimen permits controlled application of biaxial loading ratios resulting in controlled variations of crack-tip constraint for shallow surface flaws. The biaxial load ratio is defined as $P_{T} / P_{L}$, where $P_{T}$ is the total load applied to the transverse beam arms and $P_{L}$ is the total load applied to the longitudinal arms. A special test fixture was also designed and fabricated permitting testing under a uniaxial (4-point bending) loading, $P_{T} / P_{L}$ ratio of $(0: 1)$, and two biaxial (8-point bending) loading ratios, $P_{T} / P_{L}$ ratios of $(0.6: 1)$ and $(1: 1)$. The specimen and test fixture have been described extensively in prior HSST publications [3-5].

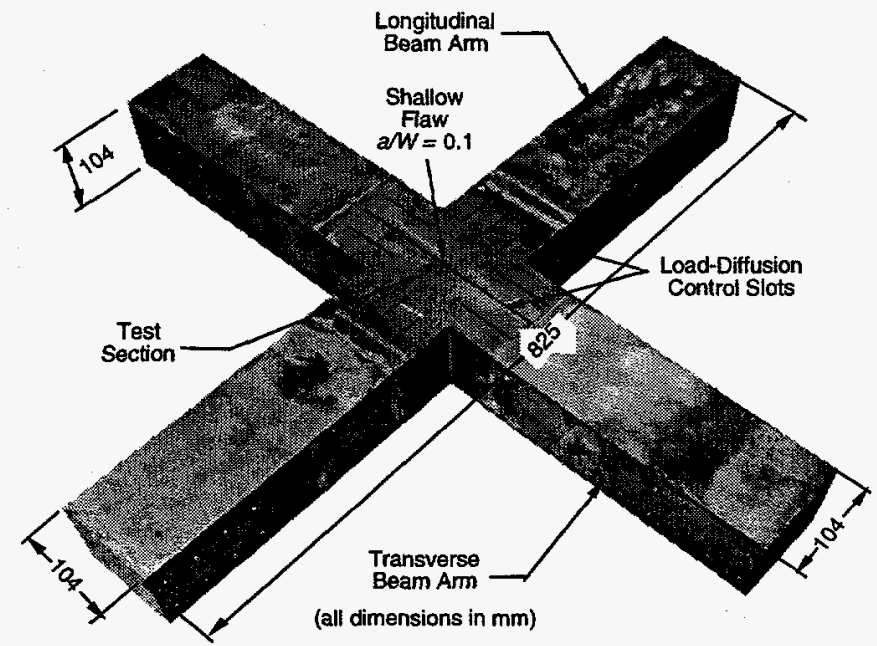

Fig. 2. Geometry of the cruciform shallow-flaw biaxial fracture toughness test specimen.

Cruciform fracture toughness data are being used to evaluate fracture methodologies for predicting the observed effects of biaxial loading on shallow-flaw fracture toughness [9-10]. As discussed in refs. [9-10] and in Part $I$ of this series[10]; initial emphasis has been placed on the assessment of stress-based methodologies, namely, the $J$. $Q$ formulation, the Dodds-Anderson toughness scaling model, and the Weibull approach. Applications of these methodologies based on a hydrostatic stress fracture criterion indicated an effect of loadingbiaxiality on fracture toughness, where the conventional maximum principal stress criterion indicated no effect. The ability of stress-strain based methodologies to predict the biaxial loading effect is also being investigated by the HSST Program $[5,12]$ as well as by other researchers [13].

Stress-based local approach methodologies adopt the Weibull stress [14] as a fracture parameter (reflecting local damage near the crack tip) that reaches a critical value at material failure. Conventional applications of the Weibull methodology utilize the maximum principal stress as the equivalent tensile stress in the kernel of the integral representation of the Weibull stress. A number of previous studies (for example, see refs. 15-17) investigated alternative fracture criteria using extended weakest-link models suitable for brittle materials (e.g., ceramics) subjected to multiaxial loading. These models consider flaws as planar cracks, with the loading expressed in terms of some suitably defined equivalent stress which depends on the orientation of the crack plane in the local stress field. Selected equivalent stress functions defined in terms of multiaxial stress components were used to evaluate failure criteria through applications to measured data.

The hydrostatic stress, applied as a critical fracture parameter, has been shown to be sensitive to the biaxial loading state near the crack tip of a cruciform specimen [9, 10]. In the early 1970s, Weiss [18] described an experimental program in which he investigated the effects of stress biaxiality on fracture strain and successfully reconciled measured data using a critical hydrostatic stress fracture criterion. More recently, the local approach using the hydrostatic stress criterion has been investigated using two- and three-parameter Weibull models to develop a scaling mechanism between uniaxial and biaxial loading states. This paper presents some preliminary results of that investigation.

\section{MATERIAL CHARACTERIZATION}

HSST Plate 14 was the source material (with chemical analysis $\mathrm{C}(0.22 \%), \quad \mathrm{P}(0.05 \%), \quad \mathrm{S}(0.003 \%), \quad \mathrm{Mo}(0.36 \%), \quad$ and $\mathrm{Ni}(0.62 \%)$ conforming to SA533, Grade B material specification requirements) for the cruciform bend specimens. This plate was selected primarily for its relatively high carbon content which made it more responsive to increasing the yield strength by heat treatment and retaining relatively uniform properties through the thickness of the plate after tempering. The base material underwent heat treatment to achieve an elevated yield strength approximating that of a typical radiation-sensitive RPV steel irradiated to a fluence of $1.5 \times 10^{19} \mathrm{n} / \mathrm{cm}^{2}$ (energy $>1 \mathrm{MeV}$ ). The heat treatment was performed successfully, providing a room temperature yield stress in the desired range (see Fig. 3.)

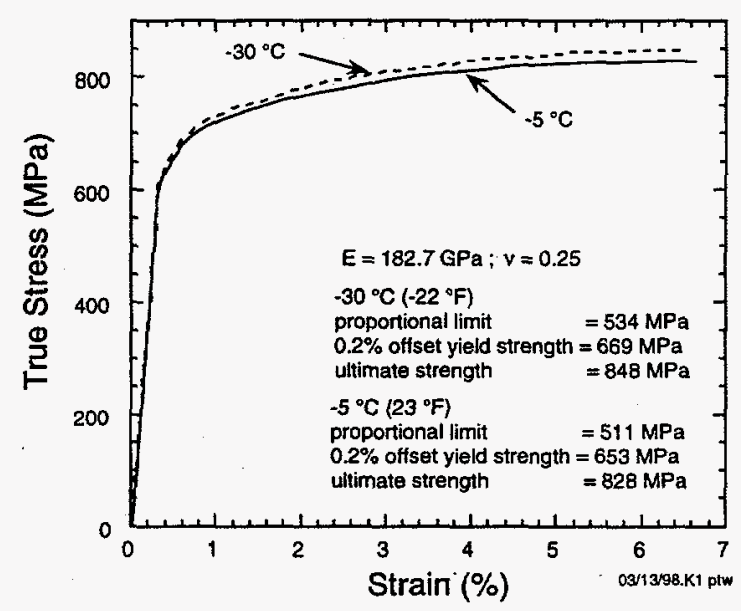

Fig. 3. Stress-strain behavior for Plate 14 material.

\section{FINITE-ELEMENT MODELS}

Three-dimensional finite-element models were developed for local crack-tip field analyses of the cruciform bend specimens subjected to uniaxial and biaxial loading. The cruciform bend specimen shown in Fig. 2 is modeled in Fig. 4, exploiting geometric 
and loading symmetries. Both blunt-crack-tip (20,754 nodes and 4317 20-node isoparametric brick elements) and sharp-crack-tip (18,775 nodes and 3886 elements) models were generated for these analyses. For the blunt-crack-tip nonlinear finite-strain elastic-plastic model, the initial finite-root-radius at the crack tip was $0.0254 \mathrm{~mm}(0.001 \mathrm{in}$.). Corresponding $J$-integrals were calculated with the small-strain elasticplastic sharp-crack-tip model to obtain a more accurate determination of $J$ as a function of loading. All models were analyzed with the ABAQUS [19] code utilizing a nonlinear elastic-plastic constitutive formulation with incremental static loading of the specimen. Temperature-dependent properties were taken from tensile characterization tests of the heat-treated Plate 14 material (see Fig. 3). All model results reported in this paper assumed a specimen temperature of $-5^{\circ} \mathrm{C}$. Also, these analyses neglected the potential impact of ductile tearing observed in two of the uniaxially loaded cruciform specimens, which were tested at $-5^{\circ} \mathrm{C}$ and failed at high toughness values.
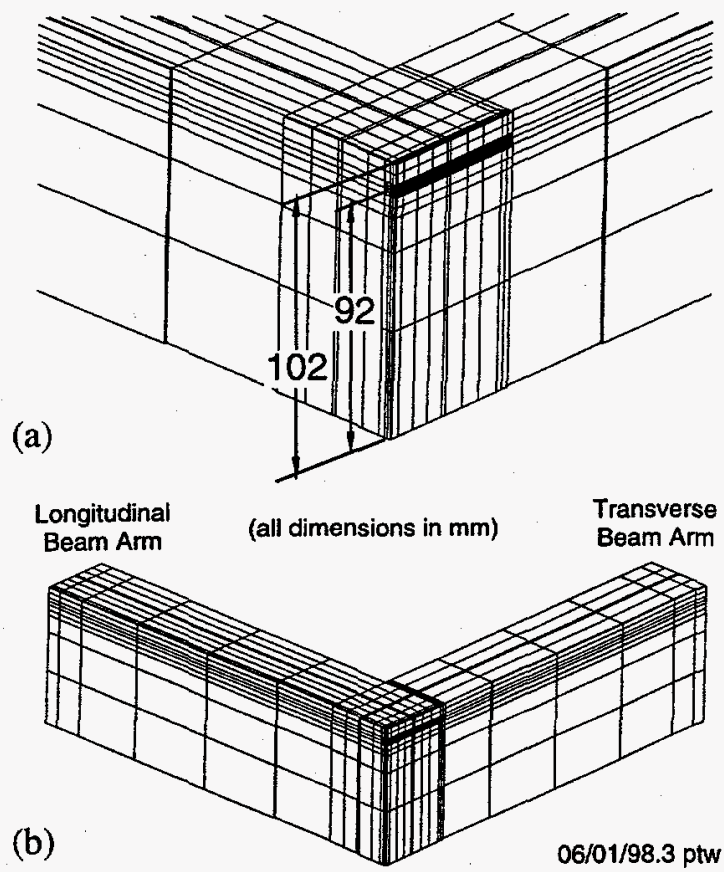

Fig. 4. Finite-element quarter-model of cruciform beam specimen: (a) detailed view of the shallow-flaw region, (b) complete mesh layout.

\section{WEIBULL STRESS ANALYSES}

The methodology implemented in the WSTRESS (Version 2.0) computer code [20] was used to study effects of biaxial loading on Weibull analyses of shallow-flaw fracture toughness data in the lower transition temperature region. The WSTRESS code employs a multiaxial form of the weakest link model applicable for a 3-D cracked solid; the Weibull stress, $\sigma_{w}$, is characterized as a fracture parameter reflecting the local damage of the material near the crack tip. The Weibull stress, $\sigma_{w}$, given by the expression

$$
\sigma_{w}=\left[\frac{1}{4 \pi V_{0}} \int_{\Omega} \int_{0}^{2 \pi} \int_{0}^{2 \pi} \sigma_{q}^{m} \sin \varphi \mathrm{d} \varphi \mathrm{d} \theta \mathrm{d} \Omega\right]^{\frac{1}{m}}
$$

is evaluated by integration of the equivalent stress, $\sigma_{q}$, over the process zone. In Eq. (1), $V_{0}$ is a reference volume; $m$ is the Weibull modulus; $\theta$ and $\varphi$ are curvilinear coordinates for integration of the tensile stress; and $\Omega$ denotes the volume of the near-tip fracture process zone, typically defined as the volume within the contour surface $\max \left(\sigma_{1}, \sigma_{2}, \sigma_{3}\right) \geq \lambda \sigma_{0}$, where $\left(\sigma_{1}, \sigma_{2}, \sigma_{3}\right)$ are the principal stresses, $\sigma_{0}$ is the yield stress, and $\lambda \approx 2$ is a constant.

\section{Fracture Criteria}

A fracture criterion must be specified to determine the equivalent (tensile) stress, $\sigma_{q}$, acting on a microcrack included into the fracture process zone. Three options for fracture criteria are implemented in the distributed version of WSTRESS [20] to evaluate the critical stress at which the crack becomes unstable: maximum principal stress (MPS), coplanar energy release (CER) rate, and normal stress averaging (NSA). Three additional fracture criteria were added to WSTRESS: the principal of independent action (PIA) [21] as proposed by Dortmans et al. [22], the noncoplanar energy release (NCER) rate [2324], and the hydrostatic stress (HYDRO) criterion, developed during the present study. These criteria are implemented using the following definitions for the equivalent tensile stress, $\sigma_{q}$ :

$$
\begin{array}{lll}
\text { MPS } & \text { Maximum Principal Stress } & \sigma_{q}=\max \left(\sigma_{1}, \sigma_{2}, \sigma_{3}\right) \\
\text { NSA } & \text { Normal Stress Averaging } & \sigma_{q}=\sigma_{n} \\
\text { PIA } & \text { Principal of Independent Action } & \sigma_{q}=\left(\mid \sigma_{1}\left\langle^{m}+\right\rangle \sigma_{2}\left\langle^{m}+\right\rangle \sigma_{3}\left\langle^{m}\right)^{\frac{1}{2}}\right. \\
\text { CER } & \text { Coplanar Energy Release Rate } & \sigma_{q}=\left(\sigma_{n}{ }^{2}+\frac{4 \tau^{2}}{(2-v)^{2}}\right)^{\frac{1}{2}} \\
\text { NCER } & \text { Noncoplanar Energy Release Rate } & \sigma_{q}=\left(\sigma_{n}{ }^{4}+6 \sigma_{n}{ }^{2} \tau^{2}+\tau^{4}\right)^{\frac{1}{4}} \\
\text { HYDRO Hydrostatic Stress } & \sigma_{q}=\frac{\operatorname{tr} \sigma}{3}=\frac{\sigma_{1}+\sigma_{2}+\sigma_{3}}{3}
\end{array}
$$

where the state of stress is defined by the principal stresses $\left(\sigma_{1}, \sigma_{2}, \sigma_{3}\right)$ and the normal $\sigma_{n}$ and shear $\tau$ stresses are calculated by

$$
\begin{array}{ll}
\text { Normal Stress } & \sigma_{n}=\sigma_{3} \sin ^{2} \varphi \cos ^{2} \theta+\sigma_{2} \sin ^{2} \varphi \sin ^{2} \theta+\sigma_{1} \cos ^{2} \varphi \\
\text { Shear Stress } & \tau^{2}=\sigma_{3}{ }^{2} \sin ^{2} \varphi \cos ^{2} \theta+\sigma_{2}{ }^{2} \sin ^{2} \varphi \sin ^{2} \theta+\sigma_{1}{ }^{2} \cos ^{2} \varphi-\sigma_{n}{ }^{2}
\end{array}
$$

Figure 5 illustrates the response of the Weibull stress function for a range of $m$ values and two definitions of $\sigma_{q}$, when applied to the Plate 14 cruciform specimen subjected to uniaxial $(0: 1)$ and biaxial (1:1) loading conditions. The equivalent stress options selected for analysis in Fig. 5 were MPS and HYDRO. For these two choices, the values of $\sigma_{q}$ are independent of microcrack location and orientation, and the Weibull stress is, therefore, 


$$
\sigma_{w}=\left[\frac{1}{V_{0}} \int_{\Omega} \sigma_{q}^{m} d \Omega\right]^{\frac{1}{m}}
$$

In Fig. 5(a), the equivalent stress was set to MPS, and the Weibull stress was then calculated for values of the modulus $m=8,10$, and 20 . No significant effects of biaxial loading were detected for the three $m$ values using the MPS criterion. In Fig. 5(b), the calculation is repeated with the equivalent stress taken as HYDRO. Differentiation between uniaxial $(0: 1)$ and biaxial (1:1) loading can be observed when the Weibull modulus $m$ is set to values of 8 and 10. By increasing the Weibull modulus to 20, any distinction between uniaxial and biaxial loading is essentially lost. Of the six candidate functions for the Weibull stress kernel listed above, only the hydrostatic stress demonstrated any sensitivity to the biaxial loading state of the cruciform specimen.

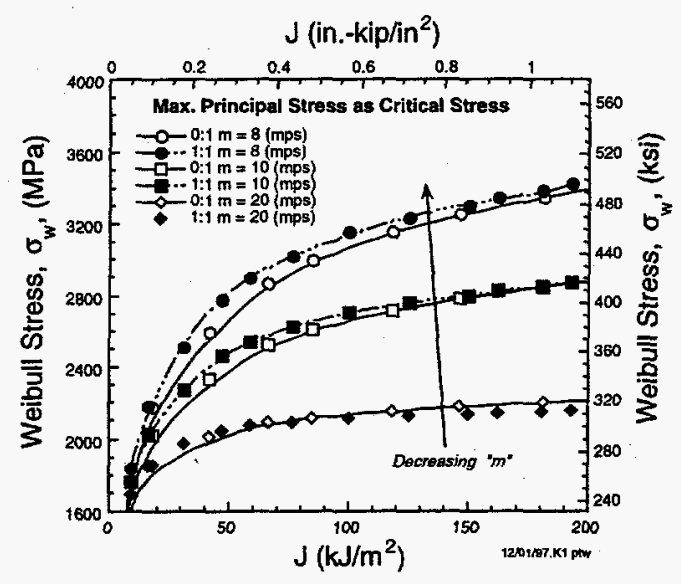

(a)

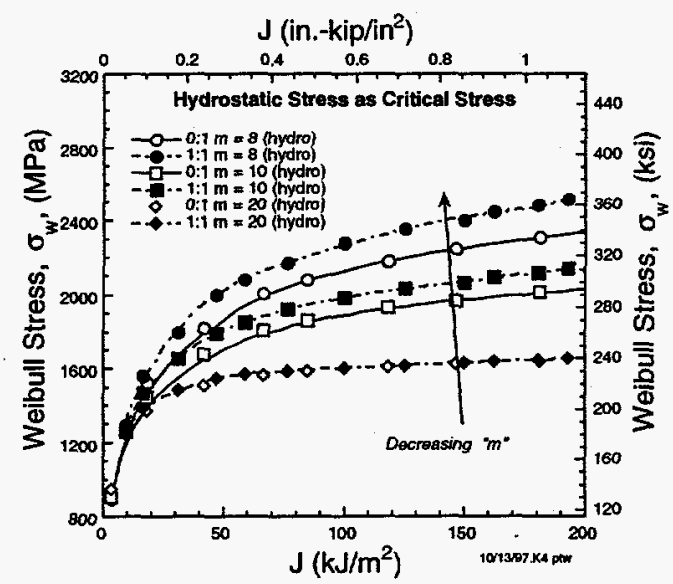

(b)

Fig. 5. Weibull stresses with (a) maximum principal stress and (b) hydrostatic stress as the equivalent stress.

\section{Probability of Cleavage Fracture}

The cumulative probability of cleavage fracture $\left(\wp_{0}\right)$ can be estimated by either a two-parameter Weibull distribution of the form

$$
\wp_{0}\left(\sigma_{w}\right)=1-\exp \left[-\left(\frac{\sigma_{w}}{\sigma_{u}}\right)^{m}\right]
$$

or a three-parameter Weibull distribution [25]

$$
\wp_{0}\left(\sigma_{w}\right)=1-\exp \left[-\left(\frac{\sigma_{w}-\sigma_{w-\min }}{\sigma_{u}-\sigma_{w-\min }}\right)^{m}\right]
$$

where the parameters of the distribution are the Weibull modulus $m$, the scaling stress (scaling factor) $\sigma_{u}$, and the minimum Weibull stress for cleavage fracture $\sigma_{w-\min }$.

The fracture parameter, $J_{C}$, can also be described by either a twoparameter Weibull distribution

$$
\wp\left(J_{c}\right)=1-\exp \left[-\left(\frac{J_{c}}{\beta}\right)^{\alpha}\right]
$$

or a three-parameter Weibull distribution

$$
\wp\left(J_{c}\right)=1-\exp \left[-\left(\frac{J_{c}-\gamma}{\beta}\right)^{\alpha}\right]
$$

where $\alpha, \beta$, and $\gamma$ are the shape, scale, and threshold parameters of the distribution, respectively. The shape and scale parameters $(\alpha, \beta)$ were estimated by the maximum likelihood method using the experimental toughness data set in Table 1. For the three-parameter models, the threshold parameter $\gamma$ is assumed to be $2.05 \mathrm{~kJ} / \mathrm{m}^{2}$ corresponding to a $K_{\min }$ of $20 \mathrm{MPa}-V_{\mathrm{m}}$ [26]. Figure 6 compares the resulting Weibull distributions (3-parameter model) in terms of the associated Weibull probability density function

$$
f\left(J_{c}, \alpha, \beta, \gamma\right)=\frac{\alpha}{\beta}\left(\frac{J_{c}-\gamma}{\beta}\right)^{\alpha-1} \exp \left(-\left(\frac{J_{c}-\gamma}{\beta}\right)^{\alpha}\right)
$$

In Fig. 6, the two curves that represent a partitioning of the data by loading state demonstrate that the highest $(1: 1)$ and the lowest $(0: 1)$ data points are located in the tails of their respective distributions.

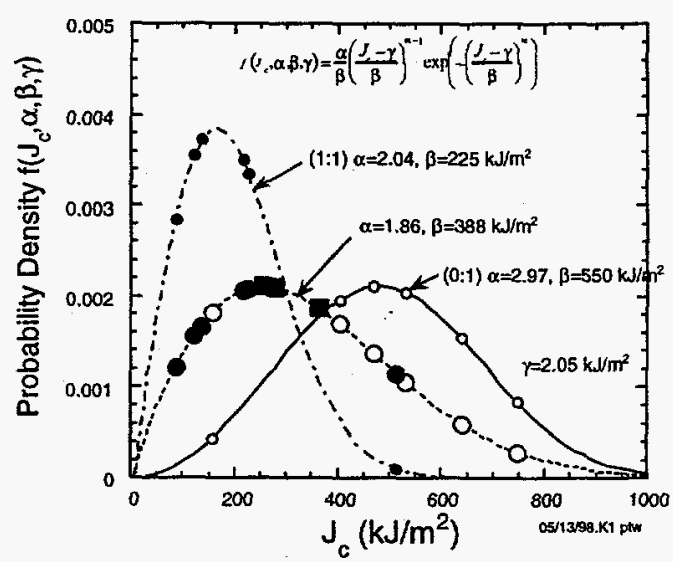

Fig. 6. Weibull probability density distributions of cruciform toughness data comparing data partitioned by loading state to complete dataset. 


\section{Weibull Model Calibration}

A new calibration scheme has been proposed by Gao, Ruggieri, and Dodds [25] to determine unique values of the Weibull parameters $\left(m, \sigma_{u}\right)$ by applying toughness data measured under low and high constraint conditions at the crack front. This new scheme (G-R-D Method) arises from the authors' experience [25] with calibration methods based on statistical inference in which they observed a strong sensitivity to the number of toughness data values $\left(J_{C}\right)$ comprising the sample population. They estimated that reliable estimates for the shape parameter, $\alpha$, in the Weibull distribution of the toughness data (see Eqs. (5) and (6)) would require many tens of $J_{c}$-values; however, fewer $J_{c}$-values (approximately 6-10) might be required to establish the median value of the distribution, $\beta$. In addition in Ref. [25], they demonstrated analytically and numerically that calibration schemes based on using only toughness data from high-constraint specimens under small scale yielding (SSY) conditions produce nonunique values of the Weibull parameters.

The new calibration scheme eliminates this nonuniqueness by mapping the available toughness data at two levels of constraint back to a small scale yielding (SSY) Weibull stress space where $\alpha$ takes on the theoretical values of $\mathbf{2}$ or 4 for Weibull distributions expressed in terms of $J_{c}$ or $K_{J c}$, respectively. In the SSY Weibull stress space, the scheme requires iterations with the Weibull modulus $m$ to determine a unique value of $\beta$ and thereby a unique $m$-value. The calibration process employs large scale yielding (LSY) toughness data from two sample populations that represent distinctly different levels of crack tip constraint. The procedure then seeks the unique $m$-value that, upon mapping the two LSY sample populations back to the corresponding SSY Weibull stress space, results in constraint-corrected toughness distributions that have the same statistical properties, specifically the same SSY Weibull distributions as described by the $(\alpha, \beta)$ parameters.

In addition to elastic-plastic analyses of the LSY specimens, the G-R-D calibration scheme also requires the results of a finite element analysis of a stationary crack under small scale yielding conditions. The plane-strain, modified boundary layer (MBL) model [27, 28] provides asymptotic crack-tip stress fields which have the general form

$$
\sigma_{i j}=\frac{K}{\sqrt{2 \pi r}} f_{i j}(\theta)+T \delta_{1 i} \delta_{1 j}
$$

where $K$ is the stress intensity factor. The special case of $T=0$ corresponds to the small scale yielding limit. An MBL finite-element model (see Fig. 7) was employed utilizing Plate 14 material property data for $-5^{\circ} \mathrm{C}$ to calculate small scale yielding (SSY) solutions corresponding to an applied Mode I loading of the finite-root-tip crack, obtained by imposing the displacements

$$
\begin{aligned}
& u_{x}(r, \theta)=\frac{K_{I}(1+v)}{E} \sqrt{\frac{r}{2 \pi}} \cos \left(\frac{\theta}{2}\right)[3-4 v-\cos \theta] \\
& u_{y}(r, \theta)=\frac{K_{I}(1+v)}{E} \sqrt{\frac{r}{2 \pi}} \sin \left(\frac{\theta}{2}\right)[3-4 v-\cos \theta]
\end{aligned}
$$

along the outer circular boundary $(r=R)$ of the model, where the stress intensity factor $K$ is related to the $J$-integral by the plane-strain formula

$$
K_{I}=\sqrt{\left(\frac{E}{1-v^{2}}\right) J}
$$

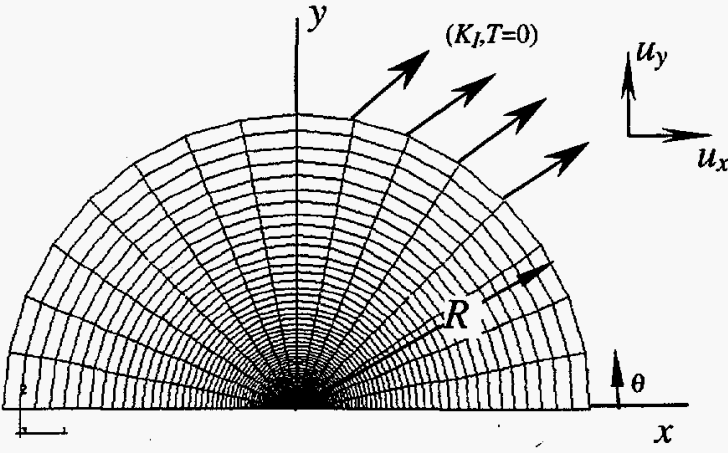

(b)

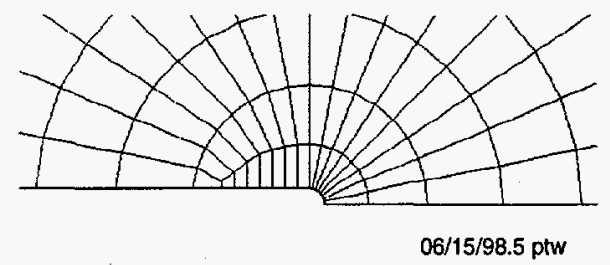

Fig. 7 Small-scale-yielding (SSY) plane-strain modified boundary layer (MBL) finite-element model: (a) global mesh layout with 16 fans, 2671 elements, and 5708 nodes; (b) close up of finite root tip with $\rho_{0}=2.54 \mu \mathrm{m} ; \rho_{0} / R=10^{-1}$.

Details of the G-R-D calibration scheme are given in [25] and its application to cruciform toughness data is described in [10]. In summary, the G-R-D scheme proceeds by the following steps:

Step 1. Test two sets of specimens (both tested under LSY conditions) with different levels of crack tip constraint. In the terminology of ref. [25], the biaxial (1:1) data are designated as Configuration A (high constraint), and the uniaxial (0:1) data are designated as Configuration B (low constraint).

Step 2. Perform detailed 3-D finite element analyses for Configurations A and B and for a plane-strain SSY model with a reference thickness adjusted to be consistent with the specimens in Configurations A or B.

Step 3. Assume a trial $m$-value, and calculate the $\sigma_{w} v s J$ histories for Configurations A and B and the SSY model. Constraintcorrect the Configuration $A$ and $B$ toughness data by mapping the data points on the $\sigma_{w}$ vs $J$ curves back to the SSY curve as shown in Fig. 8a such that $J_{c-(i)} \rightarrow J_{(i)-S S Y}$ for $\sigma_{w(x: 1)}=\sigma_{w-S S Y}$.

Step 4. Estimate $\beta_{(0: 1)}$ and $\beta_{(1: 1)}$ in SSY Weibull stress space for the two configurations by the maximum likelihood point estimate relation (without small-sample bias)

$$
\beta=\sqrt{\frac{1}{n} \sum_{i=1}^{n}\left(J_{(i)-S S Y}\right)^{2}}
$$


and calculate a relative error $R(m)$ by

$$
R(m)=\frac{\left(\beta_{(0: 1)}-\beta_{(1: 1)}\right)}{\beta_{(1: 1)}}
$$

Step 5. Repeat Steps 3 and 4 for a range of trial $m$-values and determine the $m$-value that produces an acceptably small relative error $R(m)$.

The scaling stress, $\sigma_{u}$, can then be calculated from the converged SSY- $\left(\sigma_{w-S S Y}\right.$ vs $\left.J\right)$ curve by

$$
\sigma_{u}=\sigma_{w-S y y} @ J_{S S Y}=\beta_{(0.1)}=\beta_{(: 11)}
$$

For the 3-parameter Weibull distribution, the third parameter, $\sigma_{w-\min }$, is calculated from the intercept of the $\sigma_{w-S S Y}$ vs $J$ curve at $J=2.05 \mathrm{~kJ} / \mathrm{m}^{2}\left(K_{J}=20 \mathrm{MPa}-\sqrt{\mathrm{m}}\right)$.

\section{RESULTS AND DISCUSSION}

The results of the Weibull parameter estimation using the uniaxial (0:1) and biaxial (1:1) toughness data in Table 1 are shown in Fig. 8. The Weibull stresses for the two levels of constraint were calculated for a range of Weibull moduli $m$ and then mapped back to the corresponding SSY $\sigma_{w} v s J$ curve, Fig. 8a. These constraint corrected data were then used to calculate an estimated $\beta_{(x)}$ using Eq. (11) and plotted vs $m$ (Fig. 8b). The two estimates for $\beta_{(x 1)}$ converged at $m=10.55$, Figs. $8 \mathrm{~b}-\mathrm{c}$. From the converged solution in Fig. 8a, the remaining distribution parameters can be calculated from the $\sigma_{w} v s J_{s S Y}$ curve, specifically the scaling stress is $\sigma_{u}=2074 \mathrm{MPa}$ and the minimum Weibull stress for cleavage fracture is $\sigma_{w-\min }=$. $1045 \mathrm{MPa}$. In all of the results shown in Fig. 8, the Weibull stress has been calculated using the hydrostatic stress criterion.

Figures 9 and 10 demonstrate why the maximum principal stress as the Weibull kernel produces a negligible sensitivity to biaxiality as shown in Fig. 5a and also why, at higher $m$-values, the hydrostatic stress criterion becomes invariant to biaxiality. In Fig. 9, the maximum principal stress at $J \approx 130 \mathrm{~kJ} / \mathrm{m}^{2}$, plotted as a function of the normalized distance ahead of the crack tip, is essentially independent of loading-state biaxiality. As discussed in Refs. [10-11], the cruciform specimen is not $J$-dominant at this load level for any state of biaxiality, i.e, both the maximum principal stress and hydrostatic stress profiles are not self-similar with respect to $J$ as is the case under SSY conditions. The hydrostatic stress profiles are, however, dependent on both biaxiality and $J$ in regions to the right of the peak stress, as demonstrated by the ordering by biaxiality of the $Q_{H}$-stress based on its operational definition using the hydrostatic stress in Fig. 10. Close to and to the left of the peak, the hydrostatic stress profiles become invariant to biaxiality. As the Weibull modulus increases, the high hydrostatic stresses in the region of the stress peak (approximately $r /\left(J / \sigma_{0}\right) \approx 0.7$ for $\left.J \approx 130 \mathrm{~kJ} / \mathrm{m}^{2}\right)$ become the dominant contributors

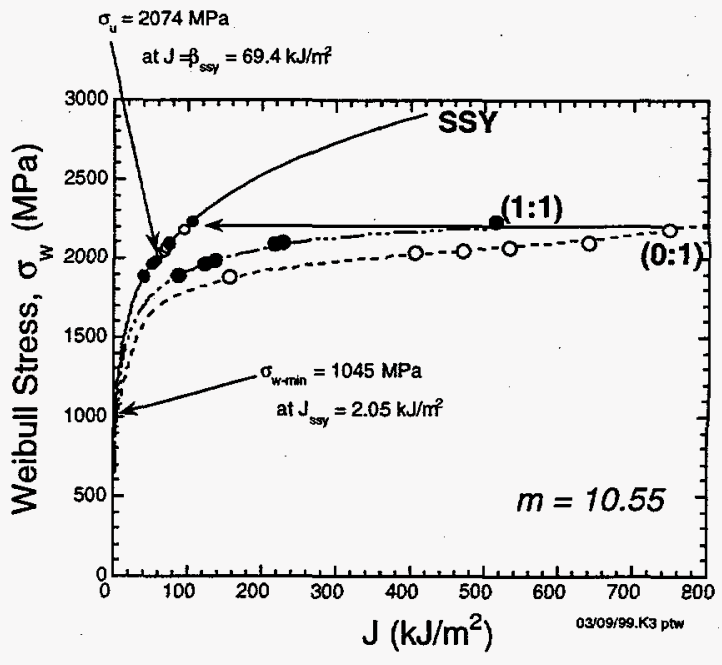

(a)

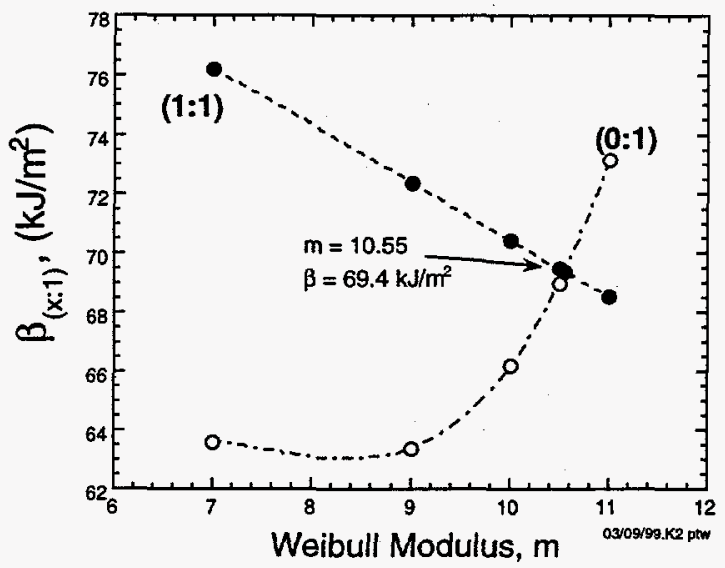

(b)

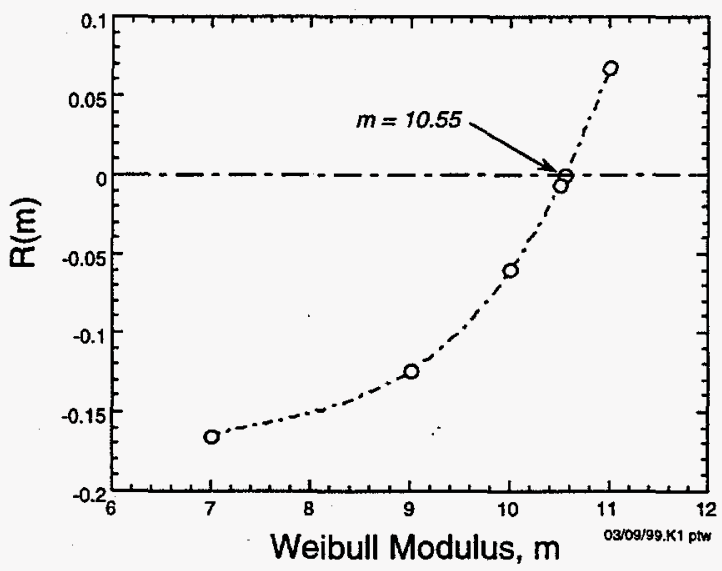

(c)

Fig. 8 Weibull parameter estimation by (a) mapping to SSY Weibull stress space: (1:1) and (0:1) mappings for $m=10.55$ and (b) estimated $\beta(x, 1)$ and (c) relative error $R(m)$ as a function of trial $m$. 
to the Weibull stress kernel (after raising to the $m$ th power in Eq. (2)) thus accounting for the invariance to biaxiality at $m=20$ in Fig. $5 b$.

The calibrated two- and three-parameter Weibull models for uniaxial $(0: 1)$ and biaxial (1:1) loadings are compared to the experimental Plate 14 toughness data in Figs. 11 and 12, respectively. The median rank probabilities assigned to the toughness data were calculated using the following estimate $[26,29-30]$ for the $i$ th data point in a sample population of $n$ data points

$$
P_{i-\text { rank }}=\frac{i-0.3}{n+0.4}
$$

where the toughness data are ranked according to increasing magnitude. The $90 \%$ confidence limits on the median rank probability estimates were calculated using an algorithm presented in Ref. [29]. The spread of these confidence limits are a function only of the toughness data sample population size, $n$.

As shown in Figs. 11a-b and 12a-b, the two-parameter models do a poor job relative to the three-parameter models (in Figs. 11c-d and 12c-d) in correlating the trends implied by the toughness data set, especially in the lower tails of the distribution. The three-parameter Weibull models enclose all of the toughness data within their confidence limits including the lower tails.

Given the calibrated Weibull model, a toughness scaling model can be constructed as shown in Fig. 13. For a given uniaxial $(0: 1)$ toughness data point, $J_{c(0: I)}$, the corresponding Weibull stress, $\sigma_{w-c}$, can be used to estimate the biaxial loading effect by projecting down to the $J_{(\mathrm{t}:)} v s \sigma_{w}$ curve along a line of constant $\sigma_{w}$ as in Fig. 13a or directly across as in Fig. $13 \mathrm{~b}$.

\section{CONCLUSIONS}

Two and three-parameter Weibull models have been calibrated using a new scheme [25] that maps toughness data from test specimens with distinctly different levels of crack-tip constraint to a SSY Weibull stress space where one of the two Weibull parameters (the shape modulus, $\alpha$ ) characterizing the toughness distribution is known and the other parameter, the scaling parameter $\beta$, can be uniquely determined by iteration on the corresponding Weibull shape modulus, $m$. These models, using the hydrostatic stress criterion in place of the more commonly used maximum principal stress in the kernel of the $\sigma_{w}$ integral definition, have been shown to correlate the experimentally observed biaxial effect in cruciform specimens in the lower transition temperature region, thereby providing a scaling mechanism between uniaxial and biaxial loading states.

\section{ACKNOWLEDGMENTS}

The authors wish to thank Professor Robert H. Dodds, Jr., University of Illinois, for his many helpful contributions to the constraint applications described in this paper. The finite-element models of the cruciform specimen were developed by J. W. Bryson, Jr.

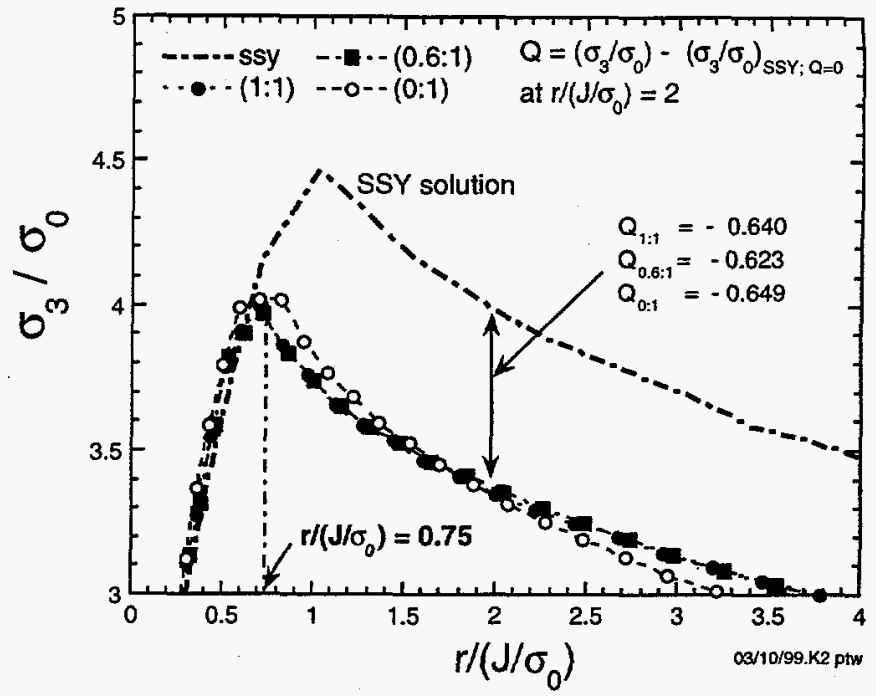

Fig. 9 Sensitivity of maximum principal (opening mode) stress to biaxiality: stress profiles along the normalized distance ahead of cruciform crack tip for $J \approx 130 \mathrm{~kJ} / \mathrm{m}^{2}$.

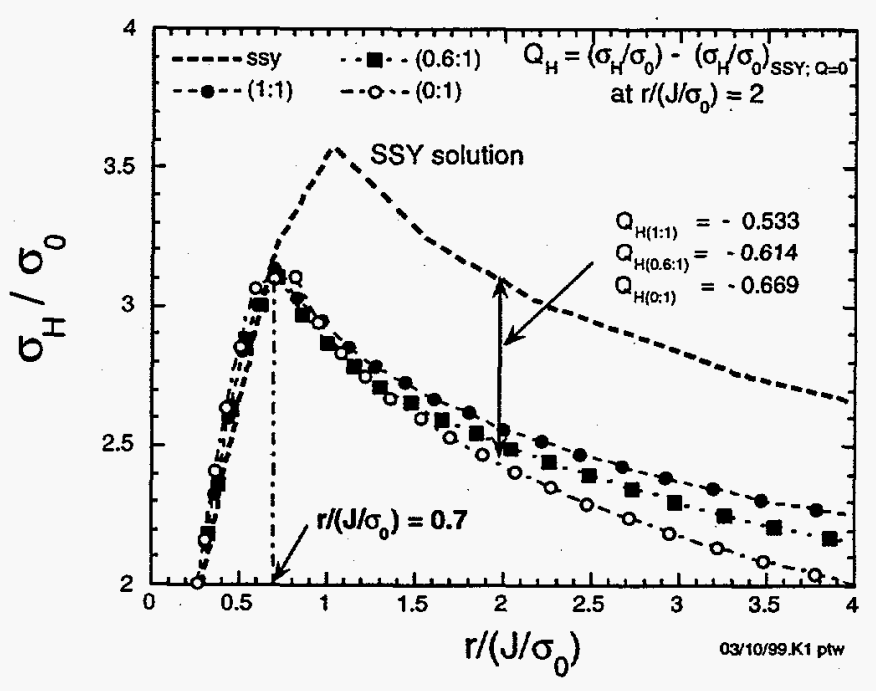

Fig. 10 Sensitivity of hydrostatic. $\left(\sigma_{H}=\sigma_{k k} / 3\right)$ stress to biaxiality: stress profiles along the normalized distance ahead of cruciform crack tip for $J \approx 130 \mathrm{~kJ} / \mathrm{m}^{2}$. 


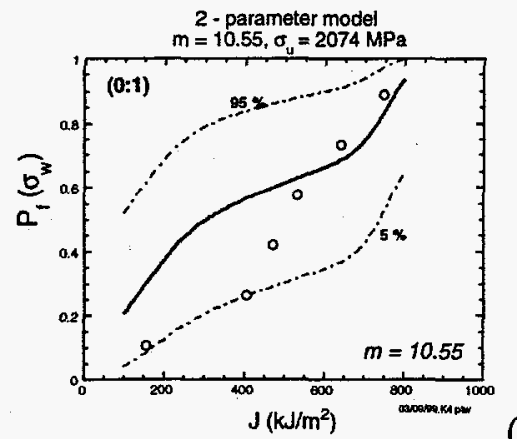

(a)

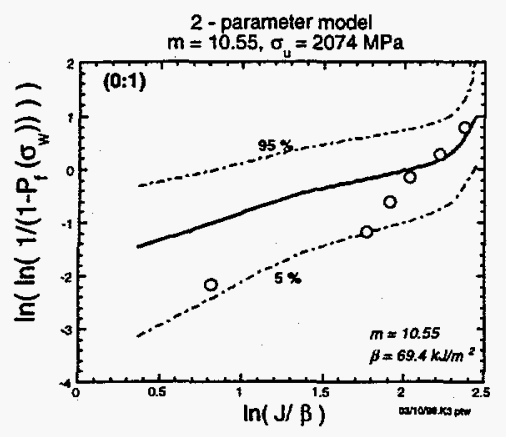

(b)

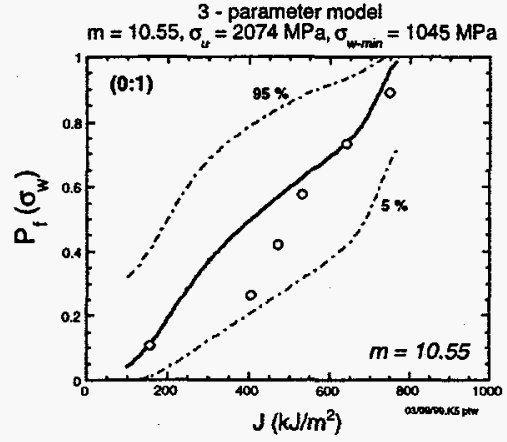

(c)

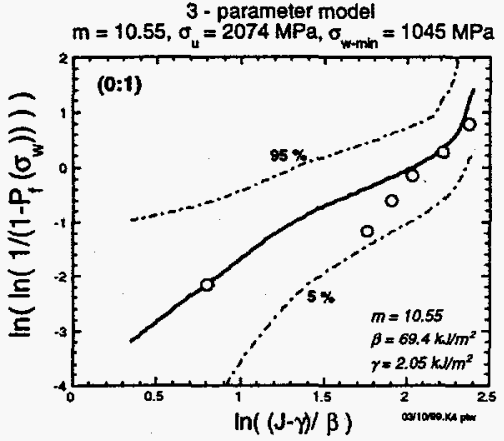

(d)

Fig. 11 Comparison of cumulative failure probabilities for uniaxial (0:1) loading using the two-parameter Weibull model of Eq. (3) in (a) standard and (b) Weibull coordinates and the three-parameter model of Eq. (4) in (c) standard and (d) Weibull coordinates for $m=10.55$.

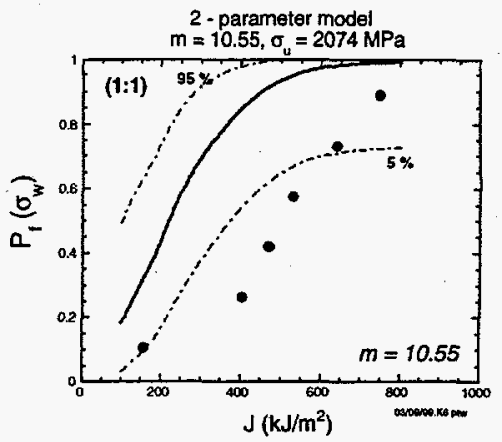

(a)

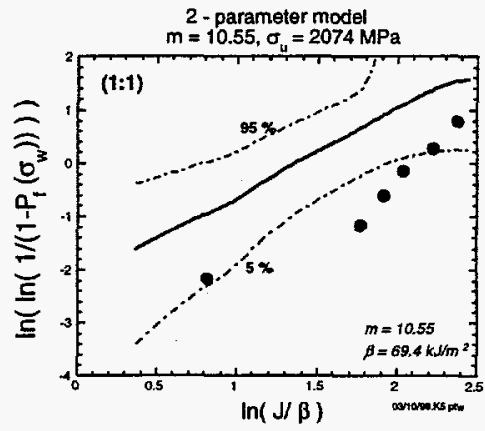

(b)

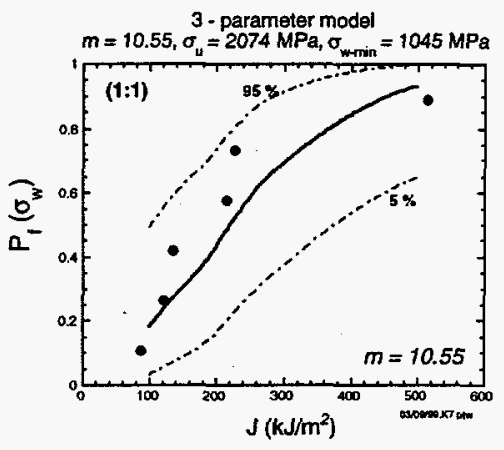

(c)

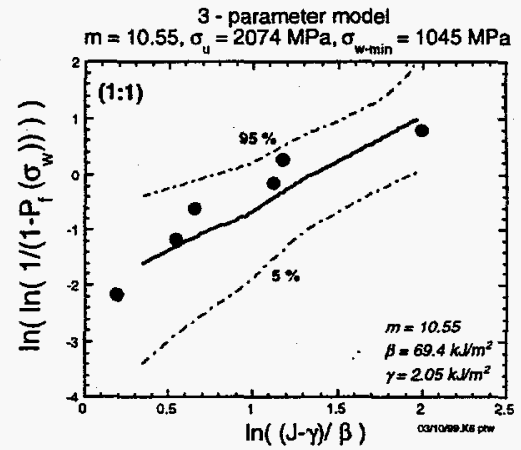

(d)

Fig. 12 Comparison of cumulative failure probabilities for biaxial (1:1) loading using the two-parameter Weibull model of Eq. (3) in (a) standard and (b) Weibull coordinates and the three-parameter model of Eq. (4) in (c) standard and (d) Weibull coordinates for $m=10.55$. 


$$
\sigma_{w}(J, m)=\left[\frac{1}{4 \pi V_{0}} \int_{\Omega}^{2 \pi} \int_{0}^{\pi} \int_{0}^{\pi} \sigma_{q}(J)^{m} \sin \varphi d \varphi d \theta d \Omega\right]^{\frac{1}{m}}
$$

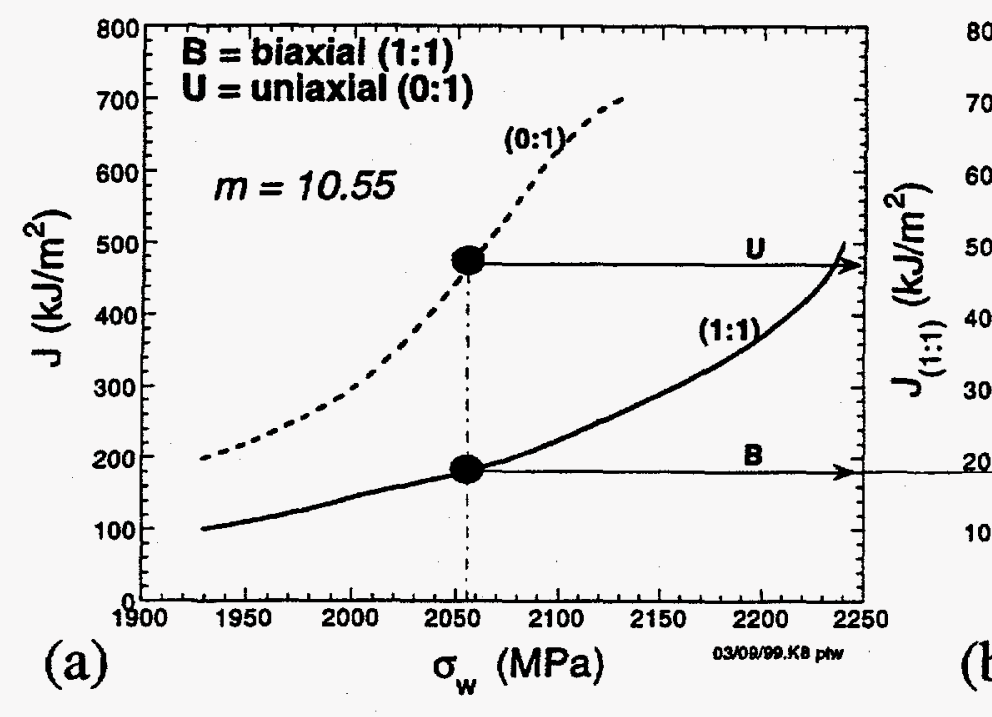

Fig. 13 (a) $J$ vs $\sigma_{w}$ trajectories for uniaxial (0:1) and biaxial (1:1) loading for $m=10.55$ and (b) toughness scaling curve for $m=10.55$ (uniaxial and biaxial toughness data are plotted along their respective axes with their probability density distribution functions from Fig. 6).

\section{REFERENCES}

1. T. H. Theiss and D. K. M. Shum, Experimental and Analytical Investigation of the Shallow-Flaw Effect in Reactor Pressure Vessels, USNRC Report NUREG/CR-5886 (ORNL/TM-12115), Oak Ridge National Laboratory, July 1992.

2. B. R. Bass, J. A. Keeney, and W. J. McAfee, "Assessment of the Fracture Behavior of Weld Material from a Full-Thickness Clad RPV Shell Segment," Fatigue and Fracture Mechanics in Pressure Vessels and Piping, ASME Pressure Vessel and Piping Conference, Honolulu, Hawaii, July 23-27, 1995, PVP-Vol. 304, pp. 299-311.

3. W. J. McAfee, B. R. Bass, and J. W. Bryson, Jr., "Development of a Methodology for the Assessment of Shallow-Flaw Fracture in Nuclear Reactor Pressure Vessels," ASME Pressure Vessel and Piping Conference, Orlando, Florida, July 27-31, 1997, PVP-Vol. 346, pp. 85-94.

4. W. E. Pennell, B. R. Bass, J. W. Bryson, Jr., T. L. Dickson, and J. G. Merkle, "Preliminary Assessment of the Effects of Biaxial Loading on Reactor Pressure Vessel Structural-IntegrityAssessment Technology," Proceedings of 4th ASME/JSME International Conference in Nuclear Engineering, New Orleans, Louisiana, March 10-14, 1996.
5. W. J. McAfee, B. R. Bass, J. W. Bryson, Jr., and W. E. Pennell, Biaxial Loading Effects on Fracture Toughness of Reactor Pressure Vessel Steel, USNRC Report NUREG/CR-6273 (ORNL/TM-12866), Oak Ridge National Laboratory, March 1995.

6. T. H. Theiss et al., Initial Results of the Influence of Biaxial Loading on Fracture Toughness, USNRC Report NUREG/CR6036 (ORNL/TM-12349), Oak Ridge National Laboratory, June 1993.

7. B. R. Bass, J. W. Bryson, T. J. Theiss, and M. C. Rao, Biaxial Loading and Shallow-Flaw Effects on Crack-Tip Constraint and Fracture Toughness, USNRC Report NUREG/CR-6132 (ORNL/TM-12498), Oak Ridge National Laboratory, January 1994.

8. B. R. Bass, W. J. McAfee, J. W. Bryson, Jr., and W. E. Pennell, "Determination of Cladding Effects on Shallow-Flaw Fracture Toughness of Reactor Pressure Vessel Steel under Prototypic Biaxial Loading," 5th International Conference on Nuclear Engineering, Nice, France, May 26-30, 1997. 
9. B. R. Bass, W. J. McAfee, P. T. Williams, and W. E. Pennell, "Evaluation of Constraint Methodologies Applied to a ShallowFlaw Cruciform Bend Specimen tested under Biaxial Loading Conditions," Fatigue, Fracture, and High Temperature Design Methods in Pressure Vessels and Piping, ASMEJJSME Joint Pressure Vessels and Piping Conference, San Diego, California, July 26-30, 1998, PVP-Vol. 365, pp. 11-25.

10. B. R. Bass, W. J. McAfee, P. T. Williams, and W. E. Pennell, "Fracture Assessment of Shallow-Flaw Cruciform Beams tested under Uniaxial and Biaxial Loading Conditions," Nuclear Engineering and Design , to appear in spring 1999.

11. B. R. Bass, W. J. McAfee, and P. T. Williams, "Investigation of Shallow Flaws under Biaxial Loading Conditions, Part I: Overview of Experimental and Analytical Studies of the Cruciform Bend Specimen," to be presented at the ASME Pressure Vessels and Piping Conference, Boston, Massachusetts, August 1-5, 1999.

12. W. E. Pennell, "Heavy-Section Steel Technology Program: Recent Developments in Crack Initiation and Arrest Research," Nuclear Engineering and Design 142, (1993) 255-266.

13. B. Z. Margolin and V. I. Kostylev, "Analysis of Biaxial Loading Effect on Fracture Toughness of Reactor Pressure Vessel Steels," International Journal of Pressure Vessels and Piping 75, (1998) 589-601.

14. C. Ruggieri and R. H. Dodds, Jr., "Probabilistic Modeling of Brittle Fracture Including 3-D Effects on Constraint Loss and Ductile Tearing," in International Conference on Local Approach to Fracture (MECAMAT 96), Fontainebleau, France, 1996.

15. A. G. Evans, "A General Approach for the Statistical Analysis of Multiaxial Fracture," Journal of the American Ceramic Society 61 (7-8), 302-308 (1978).

16. S. B. Batdorf and H. L. Heinisch, Jr., "Weakest-Link Theory Reformulated for Arbitrary Fracture Criterion," Journal of the American Ceramic Society 61 (7-8), 355-358 (1978).

17. T. Thiemeier and A. Brückner-Foit, "Influence of the Fracture Criterion on the Failure Prediction of Ceramics Loaded in Biaxial Flexure," Joumal of the American Ceramic Society 74 (1), 48-52 (1991).

18. V. Weiss, "Material Ductility and Fracture Toughness of Metals," Proceedings of the International Conference on Mechanical Behavior of Materials, Kyoto, Japan, August 15-20, 1971, The Society of Materials Science, Japan, 1972.

19. ABAQUS Theory Manual, Version 5.7, Hibbit, Karlson and Sorensen, Inc., Providence, RI, 1997.
20. C. Ruggieri and R. H. Dodds, Jr., WSTRESS 2.0: Numerical Computation of Probabilistic Fracture Parameters, Department of Civil Engineering, University of Illinois, UILU-ENG-95-2013, May 1998.

21. A. M. Freudenthal, "Statistical Approach to Brittle Fracture," Fracture: An Advanced Treatise, Vol. 2, Mathematical Fundamentals, ed. H. Liebowitz, Academic Press, New York, pp. 591-619, 1968.

22. L. Dortmans, T. Thiemeier, A. Brückner-Foit, and J. Smart, "WELFEP: A Round Robin for Weakest-Link Finite Element Postprocessors," Journal of the European Ceramic Society, 09552219/93/S6.00, Elsevier Science Publishers Ltd, England, 1993.

23. T, K. Hellen and W. S. Blackburn, "The Calculation of Stress Intensity Factors for Combined Tension and Shear Loading," International Journal of Fracture 11, (1975) 605-617.

24. J. Lamon and A. G. Evans, "Statistical Analysis of Bending Strengths for Brittle Solids: A Multiaxial Fracture Problem," Journal of the American Ceramic Society 66, (1983) 177-182.

25. X. Gao, C. Ruggieri, and R. H. Dodds, Jr., "Calibration of Weibull Stress Parameters Using Fracture Toughness Data," submitted for publication in the International Journal of Fracture, May 1998.

26. American Society for Testing and Materials, Test Method for the Determination of Reference Temperature, $T_{0}$, for Ferritic Steels in the Transition Region ASTM E 1921, 1998.

27. S. G. Larsson and A. J. Carlson, "Influence of Non-Singular Stress Terms and Specimen Geometry on Small Scale Yielding of CrackTips in Elastic-Plastic Materials," Journal of the Mechanics and Physics of Solids 21, (1973) 447-473.

28. J. R. Rice, "Limitations to the Small Scale Yielding Approximation for Crack Tip Plasticity," Joumal of the Mechanics and Physics of Solids 22, (1974) 17-26.

29. X. Gao, R. H. Dodds, Jr., R. L. Tregoning, J. A. Joyce, and R. E. Link, "A Weibull Stress Model to Predict Cleavage Fracture in Plates Containing Surface Cracks," submitted to Fatigue Fract. Engng. Mater. Struct. (1998).

30. J. G. Merkle, K. Wallin, and D. E. McCabe, Technical Basis for an ASTM Standard on Determining the Reference Temperature, $T_{O}$ for Ferritic Steels in the Transition Range, USNRC Report NUREG/CR-5504 (ORNL/TM-13631), Oak Ridge National Laboratory, November 1998. 
Table 1. Cruciform toughness data from FEM model and experimental data

\begin{tabular}{|c|c|c|c|c|c|c|c|}
\hline \multirow[b]{2}{*}{ Specimen } & \multirow{2}{*}{$\begin{array}{c}\text { Test } \\
\text { Temp. } \\
{ }^{\circ} \mathrm{C} \\
\end{array}$} & \multirow{2}{*}{$\begin{array}{c}\text { Biaxiality } \\
\text { Ratio }^{1}\end{array}$} & \multirow{2}{*}{$\begin{array}{c}\text { Failure } \\
\text { Load, } P_{L} \\
k N\end{array}$} & \multicolumn{2}{|c|}{ Toughness, $J_{c}$} & \multicolumn{2}{|c|}{ Toughness, $K_{J}$} \\
\hline & & & & $\begin{array}{l}\mathrm{FEM}^{3} \\
\mathrm{~kJ} / \mathrm{m}^{2}\end{array}$ & $\begin{array}{l}\mathrm{CMOD}^{4} \\
\mathrm{~kJ} / \mathrm{m}^{2}\end{array}$ & $\begin{array}{c}\mathrm{FEM}^{3} \\
\mathrm{MPa} \sqrt{\mathrm{m}}\end{array}$ & $\begin{array}{l}\text { CMOD }^{4} \\
\text { MPa } V_{m}\end{array}$ \\
\hline P2B.2 DT ${ }^{6}$ & -3 & $0: 1$ & 1504.4 & 433.8 & 638.65 & 290.8 & 352.8 \\
\hline P9A DT & -3 & $0: 1$ & 1529.0 & 469.8 & 747.84 & 302.6 & 381.8 \\
\hline $\mathrm{P} 13 \mathrm{~A} 2$ & -6 & $0: 1$ & 1165.1 & 177.5 & 156.71 & 186.0 & 174.8 \\
\hline$P 17 A^{25}$ & -2 & $0: 1$ & 1421.0 & $539.9^{\circ}$ & 530.94 & 324.4 & 321.7 \\
\hline $\mathrm{P} 18 \mathrm{~A}^{2,5}$ & -3 & $0: 1$ & 1329.9 & 370.9 & 403.72 & 268.9 & 280.5 \\
\hline${\mathrm{P} 19 \mathrm{~B}^{2.5}}$ & -2 & $0: 1$ & 1342.2 & 388.6 & 468.84 & 275.2 & 302.3 \\
\hline P3B & -4 & $0.6: 1$ & 1449.6 & 272.7 & 363.53 & 230.5 & 266.2 \\
\hline $\mathrm{P} 12 \mathrm{~A}$ & -6 & $0.6: 1$ & 1349.4 & 212.2 & 256.57 & 203.4 & 223.6 \\
\hline $\mathrm{P}_{15 \mathrm{~B}^{2}}$ & -4 & $0.6: 1$ & 1431.1 & 260.3 & 277.04 & 225.2 & 232.4 \\
\hline P15A & -4 & $1: 1$ & 1072.6 & 118.5 & 121.50 & 152.0 & 153.9 \\
\hline P6B & -4 & $1: 1$ & 1096.0 & 125.2 & 135.22 & 156.2 & 162.3 \\
\hline $\mathrm{P}_{17 \mathrm{~B}^{2}}$ & -5 & $1: 1$ & 932.6 & 80.5 & 85.98 & 125.2 & 129.4 \\
\hline $\mathrm{P}^{2} \mathrm{~A}^{2}$ & -3 & $1: 1$ & 1269.4 & 208.9 & 226.30 & 201.8 & 210.0 \\
\hline $\mathrm{P}^{2} \mathrm{~B}^{2}$ & -4 & $1: 1$ & 1469.9 & 404.2 & 512.64 & 280.7 & 316.1 \\
\hline $\mathrm{P}_{10 \mathrm{~B}^{2}}$ & -6 & $1: 1$ & 1246.2 & 193.9 & 214.72 & 194.4 & 204.6 \\
\hline
\end{tabular}

${ }^{\prime}$ Biaxiality ratio is the ratio of the transverse to longitudinal beam arm loads: $P_{T^{\prime}} P_{L}$

${ }^{2}$ Failure load based on equivalent $254 \mathrm{~mm}$ (10 in.) beam arm length.

${ }^{3}$ Calculated using finite-element sharp-crack model of cruciform specimen with $254 \mathrm{~mm}$ (10 in.) beam arms

${ }^{4}$ Experimental values calculated from CMOD data

${ }^{5}$ Reduced specimen test section $a / W=0.1 ; a=9.65 \mathrm{~mm}(0.38 \mathrm{in}$.); $W=96.0 \mathrm{~mm}$ (3.78 in.)

${ }^{6} \mathrm{DT}$ indicates precleavage ductile tearing 